\title{
A cluster randomised trial of educational messages to improve the primary care of diabetes
}

Robbie Foy ${ }^{1 *}$, Martin P Eccles ${ }^{2}$, Susan Hrisos ${ }^{2}$, Gillian Hawthorne ${ }^{3}$, Nick Steen ${ }^{2}$, Ian Gibb ${ }^{4}$, Bernard Croal $^{5}$ and Jeremy Grimshaw ${ }^{6}$

\begin{abstract}
Background: Regular laboratory test monitoring of patient parameters offers a route for improving the quality of chronic disease care. We evaluated the effects of brief educational messages attached to laboratory test reports on diabetes care.

Methods: A programme of cluster randomised controlled trials was set in primary care practices in one primary care trust in England. Participants were the primary care practices' constituent healthcare professionals and patients with diabetes. Interventions comprised brief educational messages added to paper and electronic primary care practice laboratory test reports and introduced over two phases. Phase one messages, attached to Haemoglobin A1c (HbA1c) reports, targeted glycaemic and cholesterol control. Phase two messages, attached to albumin: creatinine ratio (ACR) reports, targeted blood pressure (BP) control, and foot inspection. Main outcome measures comprised practice mean $\mathrm{HbA} 1 \mathrm{c}$ and cholesterol levels, diastolic and systolic BP, and proportions of patients having undergone foot inspections.

Results: Initially, 35 out of 37 eligible practices participated. Outcome data were available for a total of 8,690 patients with diabetes from 32 practices. The BP message produced a statistically significant reduction in diastolic BP (-0.62 mmHg; $95 \%$ confidence interval -0.82 to $-0.42 \mathrm{mmHg})$ but not systolic BP $(-0.06 \mathrm{mmHg},-0.42$ to 0.30 $\mathrm{mmHg}$ ) and increased the odds of achieving target BP control (odds ratio 1.05; 1.00, 1.10). The foot inspection message increased the likelihood of a recorded foot inspection (incidence rate ratio 1.26; 1.18 to 1.36). The glycaemic control message had no effect on mean HbA1c (increase $0.01 \%$; -0.03 to 0.04 ) despite increasing the odds of a change in likelihood of HbA1c tests being ordered (OR 1.06; 1.01, 1.11). The cholesterol message had no effect (decrease $0.01 \mathrm{mmol} / \mathrm{l},-0.04$ to 0.05 ).
\end{abstract}

Conclusions: Three out of four interventions improved intermediate outcomes or process of diabetes care. The diastolic BP reduction approximates to relative reductions in mortality of 3\% to 5\% in stroke and 3\% to $4 \%$ in ischaemic heart disease over 10 years. The lack of effect for other outcomes may, in part, be explained by difficulties in bringing about further improvements beyond certain thresholds of clinical performance.

Trial Registration: Current Controlled Trials, ISRCTN2186314.

\footnotetext{
* Correspondence: r.foy@leeds.ac.uk

${ }^{1}$ Leeds Institute of Health Sciences, Charles Thackrah Building, University of

Leeds, 101 Clarendon Road, Leeds LS2 9LJ, UK

Full list of author information is available at the end of the article
} 


\section{Background}

Despite continuing improvements in the delivery and outcomes of care for people with diabetes [1-3] there is still evidence of substantial inappropriate variations [4-8]. A systematic review of quality improvement strategies for patients with type 2 diabetes indicated small to modest effects on glycaemic control [9]. Much work remains to be done in developing and evaluating many quality improvement strategies given that they are often resource-intensive and the difficulties in reliably identifying their 'active ingredients' [10].

Across a range of different targeted clinical behaviours and contexts, in general reminders delivered to healthcare professionals consistently improve performance [11], an effect also apparent with point-of-care computer reminders [12]. However, the optimal configuration of such reminders is still unclear. One approach that offers the potential advantages of simplicity and sustainability is attaching brief educational messages to the results of tests ordered in the expectation that the healthcare professional who ordered the test will read and act on the message when the result is delivered back to the practice. Attached to radiology reports ordered from primary care, such an intervention reduced requests for targeted $\mathrm{x}$-rays without compromising quality of referrals [13]. Messages attached to test reports also reduced primary care laboratory test requests [14].

However, previous research on interventions to change test ordering-related behaviour has largely focused on either decreasing the overall volume of tests ordered (in the implicit belief that some are unnecessary) or specifically decreasing the number of inappropriate tests ordered; 47 out of 49 studies in one review focused on such reductions [15]. Less is known about the effectiveness of test ordering messages in improving wider aspects of clinical management to promote evidence-based care.

In one primary care trust in the north east of England, we evaluated the effects on the care provided for patients with type 2 diabetes of educational prompts attached to laboratory test reports and aimed at increasing evidence-based clinical practice.

\section{Methods}

\section{Study design}

The study used a cluster randomised controlled trial design, described in detail elsewhere [16], with primary care practices as the unit of randomisation.

\section{Participants, setting and context}

The study participants were the clinicians-general practitioners (GPs) and nurses-working in those primary care practices in Newcastle upon Tyne that used the laboratory services of the Newcastle Hospitals NHS Trust (now the Newcastle Hospitals NHS Foundation Trust). Outcomes were assessed on all those patients registered with each practice and with a diagnosis of diabetes whose care was undertaken either by the practice or shared between the practice and hospital.

The study started in late 2005, one year after the advent of performance-related funding for primary care physicians [17]. Through the Quality and Outcomes Framework (QOF), practices earned points for achieving targets across a range of clinical and organisational indicators. Performance against these targets can generate up to $40 \%$ of practice income. The QOF initially included 18 diabetes indicators that were extended or modified over subsequent years [18].

\section{Interventions}

The interventions were four brief educational messages, typically of less than 30 words, added to the returned results of laboratory tests ordered by clinicians on patients with diabetes cared for in intervention practices. The educational messages were developed by a multidisciplinary group that included clinical representatives from primary care, secondary care, laboratory services, and the research team. The messages gave succinct evidence-based, educational information regarding appropriate patient management congruent with the local diabetes clinical guideline (Table 1). The message topics were selected because of their clinical importance, and the feasibility of being able to measure improvements in relevant outcomes from routinely held data in primary care practices.

The interventions were introduced in two phases. In phase one (December 2005), messages were attached to electronic and paper Haemoglobin A1c (HbA1c) test reports. The messages were of two types. The first message related to glycaemic control, was conditional on the HbA1c level, and gave advice about appropriate treatment. The second type of message gave a non-conditional message relating to cholesterol control.

In phase two (October 2006), messages were attached to albumin:creatinine ratio (ACR) test reports and were also of two types. The first message related to blood pressure (BP) control, was conditional on the ACR level, and gave advice on target BP levels for patients with and without a diagnosis of microalbuminuria. The second message related to foot inspection and was nonconditional.

\section{Intervention fidelity}

We contacted at least two practices in each of the four study arms at six-month intervals (different practices each time) to check whether practices were receiving 
Table 1 Content of the laboratory test messages

\begin{tabular}{|c|c|c|}
\hline $\begin{array}{l}\text { Study } \\
\text { phase }\end{array}$ & Type and attachment of message & Content of message \\
\hline \multirow[t]{2}{*}{$\begin{array}{l}\text { Phase } \\
\text { One }\end{array}$} & Unconditional; attached to all cholesterol reports & $\begin{array}{l}\text { For type } 2 \text { diabetes and age } \geq 40 \text { yrs: on simvastatin } 40 \text { mg? See [local } \\
\text { guideline] for detail and exclusions }\end{array}$ \\
\hline & Conditional; attached to all HbA1c reports & $\begin{array}{l}\text { If } \mathrm{HbA} 1 \mathrm{c}<6.5 \% \\
\text { 'Within target for type } 2 \text { diabetes' } \\
\text { If } \mathrm{HbA} 1 \mathrm{c} 6.5 \text { to } 7.0 \% \\
\text { 'For type } 2 \text { diabetes, consider increasing oral therapy' } \\
\text { If HbA1c } 7.0 \text { to } 8.0 \% \\
\text { 'If type } 2 \text { diabetes: on max oral therapy, e.g., Metformin } 1 \mathrm{G} \text { BD + gliclazide } 160 \\
\text { mg BD?' } \\
\text { If HbA1c }>8.0 \% \\
\text { 'If type } 2 \text { diabetes, consider insulin if on max oral Rx, e.g., Metformin } 1 G \text { BD + } \\
\text { gliclazide } 160 \text { mg BD' }\end{array}$ \\
\hline \multirow[t]{2}{*}{$\begin{array}{l}\text { Phase } \\
\text { Two }\end{array}$} & $\begin{array}{l}\text { Unconditional; attached to all albumin: creatinine ratio } \\
\text { (ACR) test reports }\end{array}$ & $\begin{array}{l}\text { 'Newcastle Diabetes Guideline Footcare: all patients annual review of sensation, } \\
\text { pulses, footwear education' }\end{array}$ \\
\hline & Conditional; attached to all ACR test reports & $\begin{array}{l}\text { If ACR above } 2.5 \\
\text { 'If confirmed microalbuminuria: aim for BP }<130 / 80 \text { in type } 2 \text { diabetes' } \\
\text { If ACR below } 2.5 \\
\text { 'If no microalbuminuria: aim for BP control }<140 / 80 \text { in type } 2 \text { diabetes' }\end{array}$ \\
\hline
\end{tabular}

their allocated messages, and that the messages continued over the intervention period as planned

\section{Randomisation}

In each of two phases primary care practices were randomised twice to receive or not each of two educational messages. Thus, in each phase $25 \%$ of practices received both messages, $25 \%$ each received one of the messages, and $25 \%$ received no intervention. For phase one, primary care practices were randomised twice to receive or not the glycaemic educational messages and to receive or not the cholesterol educational messages. Randomisation was stratified using existing routine data by both the number of patients with diabetes per practice (using a median split of 200) and the proportion of patients with an HbA1c of $7.4 \%$ or less (grouped by less than $60 \%, 60 \%$ to $70 \%$, and over $70 \%$ ) [17].

For phase two, ten months later, practices were randomised twice to receive or not the foot inspection reminder message and to receive or not the BP educational messages. On this occasion randomisation was stratified by practice QOF scores for recorded foot examination (median split of 2.85 points out of 3 ) and the proportion of patients with a record of BP of $145 / 85 \mathrm{mmHg}$ or less (using median split of $74.8 \%$ ). All randomisations were conducted independently by a statistician using numbers randomly generated by computer.

\section{Outcomes}

The main outcomes were the primary care practices' mean levels of $\mathrm{HbA} 1 \mathrm{c}$, cholesterol and BP, and numbers of patients with recorded foot inspections in the previous calendar month. Other analysed outcomes were: the number of patients within target ranges for $\mathrm{HbAlc}$, cholesterol, and BP; the number of HbA1c, cholesterol, and ACR tests requested (standardised for practice size); and mean practice BP levels for patients with and without recorded microalbuminuria (operationalised as a record of two or more consecutive ACRs of 2.5 or greater).

\section{Data collection}

National Health Service (NHS) staff collected coded data from practice computer systems using customised electronic queries. They were not blinded to group assignment. They removed patient identifiers before the transfer of data to the research team. For phase one interventions, there were 24 and 34 months of pre- and post-intervention outcome data, respectively, whilst for phase two interventions, there were similarly 34 and 24 months of data. This produced multiple observations for patients over the study. In general, practices routinely collect and code patient data that contribute to the calculation of scores for the QOF [17]. Our data were similar (though not identical) to these and within QOF practices are subject to independent scrutiny of their data for accuracy and completeness, thereby allowing a considerable degree of confidence in data quality, though we did not independently assess this.

\section{Sample size}

The sample size calculations, based on methods described by Donner et al. [19], were undertaken using a programme developed by Campbell et al. [20]. They were based upon the following assumptions: 34 participating practices each with a mean number of 62 patients with diabetes; a significance level of $5 \%$; $80 \%$ power; and an intra-class correlation coefficient (ICC) of 
0.2 for process measures (based upon recording of blood pressure and $\mathrm{HbA} 1 \mathrm{c}$ for an earlier trial [21]) and 0.05 for intermediate outcomes [22]. With these assumptions, we would be able to detect a $21 \%$ improvement (from $55 \%$ to $76 \%)$ in a binary outcome measure (e.g., foot examination) and an effect size of 0.25 in a continuous outcome measure. The latter represents changes of $0.36 \%$ in mean $\mathrm{HbA} 1 \mathrm{c}, 0.27 \mathrm{mmol} / \mathrm{L}$ in mean cholesterol, $4.98 \mathrm{mmHg}$ in mean systolic $\mathrm{BP}$, and $2.55 \mathrm{mmHg}$ in mean diastolic BP.

\section{Analysis}

The analytic strategy differed from that given in the published protocol [16]. First, we were able to run the study over a longer period than initially anticipated, giving us the opportunity to capitalise on the fact that we could collect data over an extended period of time. An interrupted time series analysis approach allowed use of all the available data rather than reducing them to single observations per patient pre- and post-intervention [23]. Second, analyses were also adjusted to take account of factors used to stratify randomisation.

Only observations made after a patient was first diagnosed with diabetes were included in the analysis. For continuous dependent variables (BP, HbA1c and cholesterol values), a three-level, multilevel model incorporating random variation between practices, random variation between patients within practices, and random variation between repeated measures within patients was used to investigate the impact of the interventions. The following fixed effects were investigated: general trends in the dependent variable over time; a difference between intervention and control practices across the entire period of investigation; and a difference between observations made prior to the relevant intervention and those made after. Fitting an interaction between the last two effects then provided an estimate of the effect of the intervention.

The continuous variables were also dichotomised: patients were categorised as being above (not controlled) or below (controlled) target thresholds described in the educational messages. These binary variables were analysed using a three-level, multilevel model as described above except that a binomial error structure was assumed for the random variation at the lowest level of the model.

To investigate the effect of the intervention on rates of foot inspection and rates of test ordering, the dependent variable was the number of patients for whom a foot inspection or test result was recorded in a practice in a calendar month. This was analysed using a two-level, negative binomial regression model with months nested within practices. The log of the number of patients with diabetes in the practice during the month was included as an offset. The effects of the interventions were then estimated using the approach described above for the continuous variables.

\section{Ethical approval}

The study was approved by the Newcastle and North Tyneside Research Ethics Committee (Reference number 05/Q0905/95).

\section{Results}

Of 37 eligible practices, 35 agreed to participate and two declined. By the time of outcome data collection, two practices had merged into one (both cholesterol message-only practices at first randomisation, whilst one received both messages and one foot inspection messages only at second randomisation) and a further practice had closed (glycaemic and cholesterol messages only). Following inspection, clinical data were considered unusable for one control practice (which appeared to be using $\mathrm{HbA1c}$ as a diagnostic as well as monitoring test) and it was therefore excluded from the analysis. Thus outcome data were available for 32 practices. We identified a total of 8,690 patients with diagnoses of type 2 diabetes made before or during the study period. Table 2 shows the baseline characteristics of study practices and their patients. The CONSORT diagrams (Figures 1 and 2) summarise the flows of recruitment, participation, and analysis.

We checked with 18 practices as to whether they were receiving allocated interventions. For the eight various possible combinations of the four intervention messages, at least two practices per combination confirmed receipt of the messages as allocated. There were no cases of practices receiving an unallocated message.

The mean intra-cluster correlations (ICCs) at baseline were 0.03 (95\% CI: 0.02, 0.05) for HbA1c, 0.04 (0.02, 0.07) for systolic BP, $0.02(0.01,0.03)$ for diastolic BP, and $0.06(0.03,0.1)$ for cholesterol. For foot inspection, the corresponding figures were $0.34(0.28,0.53)$, reflecting large systematic differences between practices in the recording of this variable.

In general, the clinical values were already reasonable, with baseline control group mean values of HbA1c of $7.4 \%$, cholesterol of $4.5 \mathrm{mmol} / \mathrm{l}$, and BP of $147 / 80$ mmHg. Figures 3, 4 and 5 show the intervention and control trends in their values over the study period. Table 3 shows the estimated effects of the interventions based on the multilevel models.

There was no intervention effect on HbA1c (increase $0.1 \%$; $95 \%$ CI $-0.03,0.04$ ) or good glycaemic control (HbA1c less than 6.35\%; OR 0.94; 95\% 0.87, 1.03). However, the intervention produced an increase in the likelihood of a test being ordered (IRR 1.06; 95\% CI 1.01, 1.11). 
Table 2 Pre-intervention characteristics of intervention and control groups.

\begin{tabular}{|c|c|c|c|}
\hline Trial intervention & Pre-intervention characteristics & Intervention group & Control group \\
\hline \multirow[t]{9}{*}{ Glycaemic control } & Practice factors & & \\
\hline & Number & 18 & 16 \\
\hline & Median number of partners & 4.5 & 4 \\
\hline & Mean (SD) list size & $7,082(3150)$ & $8,170(7071)$ \\
\hline & Patient factors & & \\
\hline & Mean (SD) number in practice & $196(108)$ & $205(120)$ \\
\hline & Mean age (years, SD) & $65(14)$ & $63(14)$ \\
\hline & Proportion men (\%) & 52 & 53 \\
\hline & Mean (last recorded) HbA1c (SD) & $7.4(1.4)$ & $7.4(1.4)$ \\
\hline \multirow[t]{9}{*}{ Cholesterol control } & Practice factors & & \\
\hline & Number & 18 & 16 \\
\hline & Median number of partners & 4 & 4 \\
\hline & Mean (SD) list size & $7,455(7049)$ & $7,775(2890)$ \\
\hline & Patient factors & & \\
\hline & Mean (SD) number in practice & $188(109)$ & $213(117)$ \\
\hline & Mean age (years, SD) & $64(14)$ & $64(14)$ \\
\hline & Proportion men (\%) & 52 & 53 \\
\hline & Mean (last recorded) cholesterol $(\mathrm{mmol} / \mathrm{l})$ & $4.7(1.2)$ & $4.5(1.1)$ \\
\hline \multirow[t]{10}{*}{ Blood pressure control } & Practice factors & & \\
\hline & Number & 17 & 17 \\
\hline & Median number of partners & 5 & 4 \\
\hline & Mean (SD) list size & $7,433(3085)$ & $8,117(6971)$ \\
\hline & Patient factors & & \\
\hline & Mean (SD) number in practice & $239(128)$ & $200(116)$ \\
\hline & Mean age (years, SD) & $65(14)$ & $63(14)$ \\
\hline & Proportion men (\%) & 53 & 53 \\
\hline & Mean (last recorded) systolic BP (mmHg) & 145 & 147 \\
\hline & Mean (last recorded) diastolic BP $(\mathrm{mmHg})$ & 80 & 80 \\
\hline \multirow[t]{9}{*}{ Foot examination } & Practice factors & & \\
\hline & Number & 17 & 17 \\
\hline & Median number of partners & 4 & 4 \\
\hline & Mean (SD) list size & 7,449 (3188) & $8,133(7015)$ \\
\hline & Patient factors & & \\
\hline & Mean (SD) number in practice & $223(105)$ & $218(139)$ \\
\hline & Mean age (years, SD) & $64(14)$ & $64(14)$ \\
\hline & Proportion men (\%) & 51 & 54 \\
\hline & Proportion with a recorded foot inspection in the previous 15 months (\%) & $2536(69)$ & $2761(78)$ \\
\hline
\end{tabular}

There was no intervention effect on mean cholesterol levels, whether or not cholesterol was within target range or cholesterol testing rates.

For systolic BP, there was a mean annual reduction of 1.59 (95\% CI 1.49, 1.69) $\mathrm{mmHg}$ during the study period, but no intervention effect. For diastolic BP, there was a mean annual reduction of 0.92 (95\% CI 0.81, 1.02) $\mathrm{mmHg}$ during the study period, and a statistically significant reduction $(-0.52(95 \% \mathrm{CI}-0.73,-0.32) \mathrm{mmHg}$ in intervention practices. The intervention increased the odds of patient BP being controlled at or under 140/80 (OR 1.05 (95\% CI 1.00, 1.10).

For the BP analyses, we also considered the possibility of a delayed effect given the time taken for clinical review and treatment titration of patients with raised BP. We therefore undertook an exploratory post hoc analysis, fitting a delayed effect to the model that assumed a gradual increase in the intervention effect 

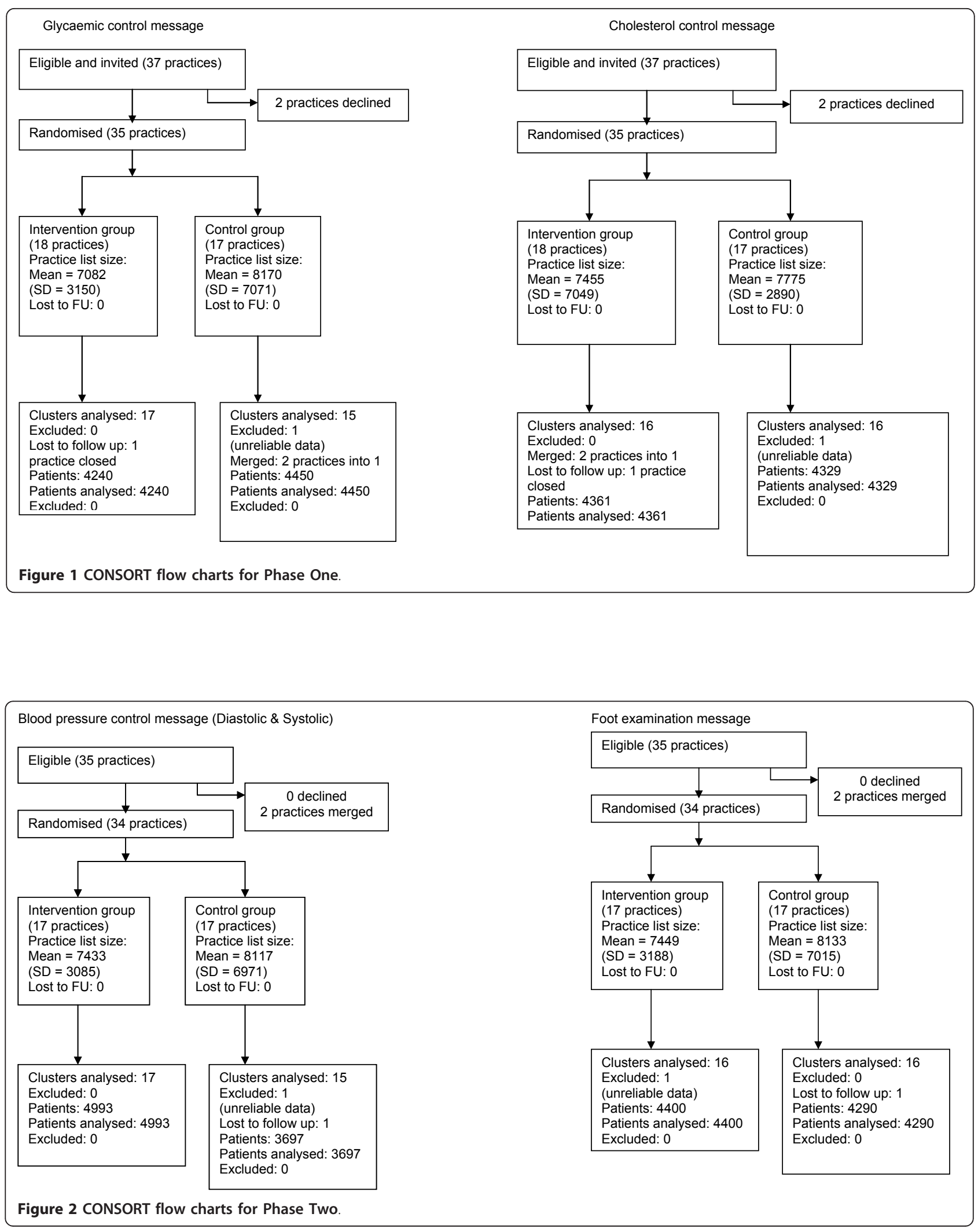


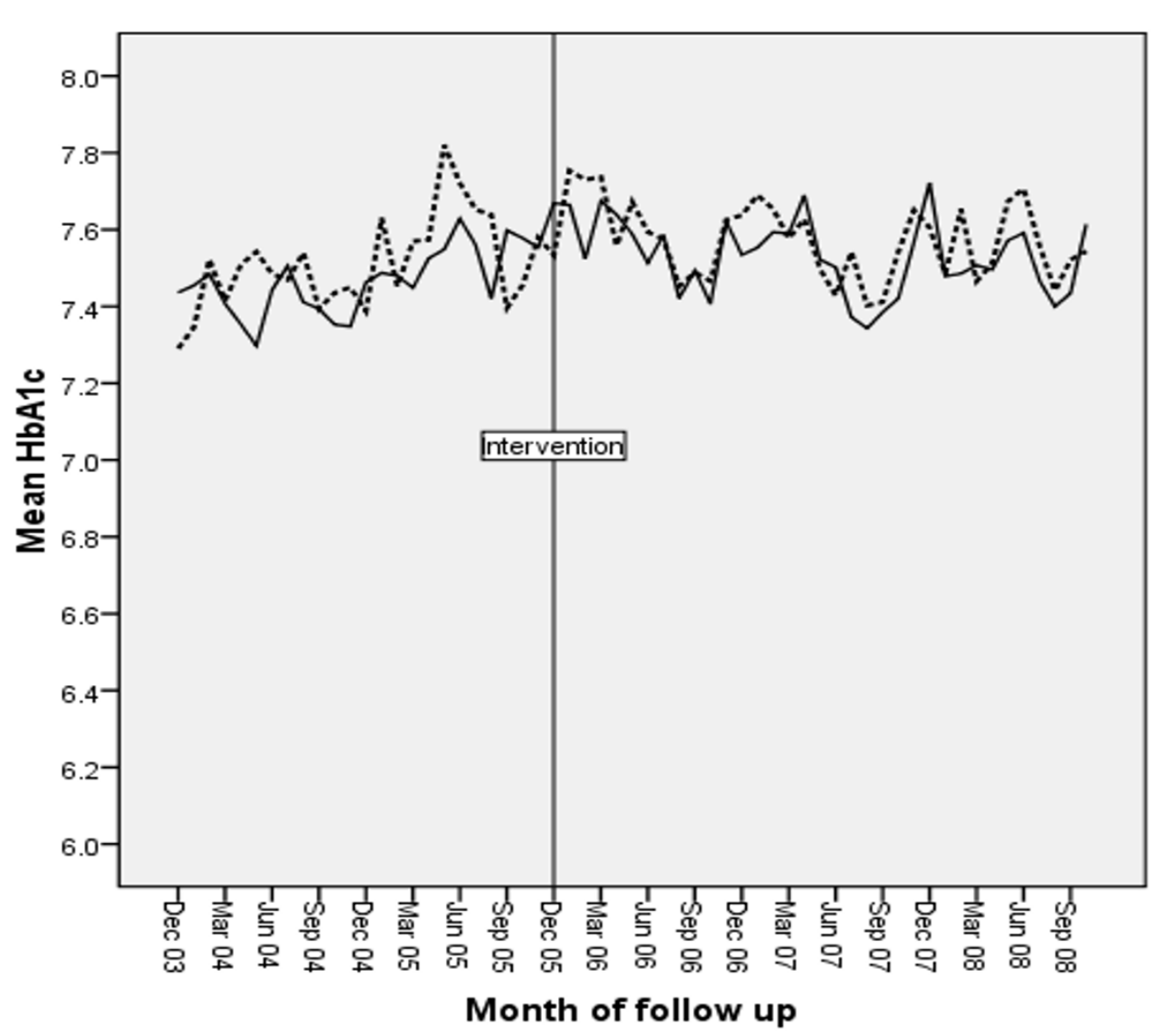

$\mathrm{HbA1c}$ message
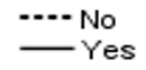

Figure 3 Mean $\mathrm{HbA} 1 \mathrm{c}$ during period of study by calendar month.

over a four month period. This analysis found no evidence of a delayed effect.

For foot examination, there was an increased likelihood of a recorded foot inspection (IRR 1.26; 95\% CI $1.18,1.36)$ in intervention practices.

The BP analyses planned for patients with microalbuminuria were constrained by missing data because ACR results were only available from a subset of 21 of the 32 practices included in the final analysis. In these 21 practices (comprising 14 and seven of the intervention and control groups, respectively) there were 5,765 patients who each contributed between one and 108 BP measurements over the study period $(79,135$ measurements in total). There were 1,019 patients with two or more consecutive ACR values greater than 2.5 (18,358 BP measurements in total corresponding to these patients). In patients with microalbuminuria, mean systolic BP increased by $1.38(0.33,2.42) \mathrm{mmHg}$, whilst there was a non-significant increase in diastolic BP of $0.61(-0.03,1.19) \mathrm{mmHg}$.

The intervention reduced the odds of a patient with microalbuminuria having their blood pressure controlled at or under $130 / 80 \mathrm{mmHg}$ (OR 0.88; 95\% CI 0.78, 0.99).

\section{Discussion}

Three of the four educational messages accompanying laboratory test reports influenced clinical behaviour for two primary outcomes (BP and foot inspections) and one secondary outcome (HbA1c testing). Patient endpoints improved, with a small decrease in diastolic BP and an increase in the proportion of patients with controlled BP, and processes of care changed, with increased likelihoods of recorded foot inspections and HbA1c testing. Where they occurred, the effects appeared immediately after initiation of the messages. Once established, given its automated nature, this intervention is likely to be easily sustainable. These effects were achieved against a background of improving performance accelerated by financial incentives [3]; the average overall percentage level of achievement for the QOF diabetes indicators had improved over 2005 to 2009 from $93.2 \%$ to $98.4 \%$ in England and from $97.9 \%$ to $99.7 \%$ in Newcastle upon Tyne [18]. Furthermore, in a recent comparative audit, the primary care trust in Newcastle was ranked first out of 152 trusts in England in having the highest percentage of people with diabetes 


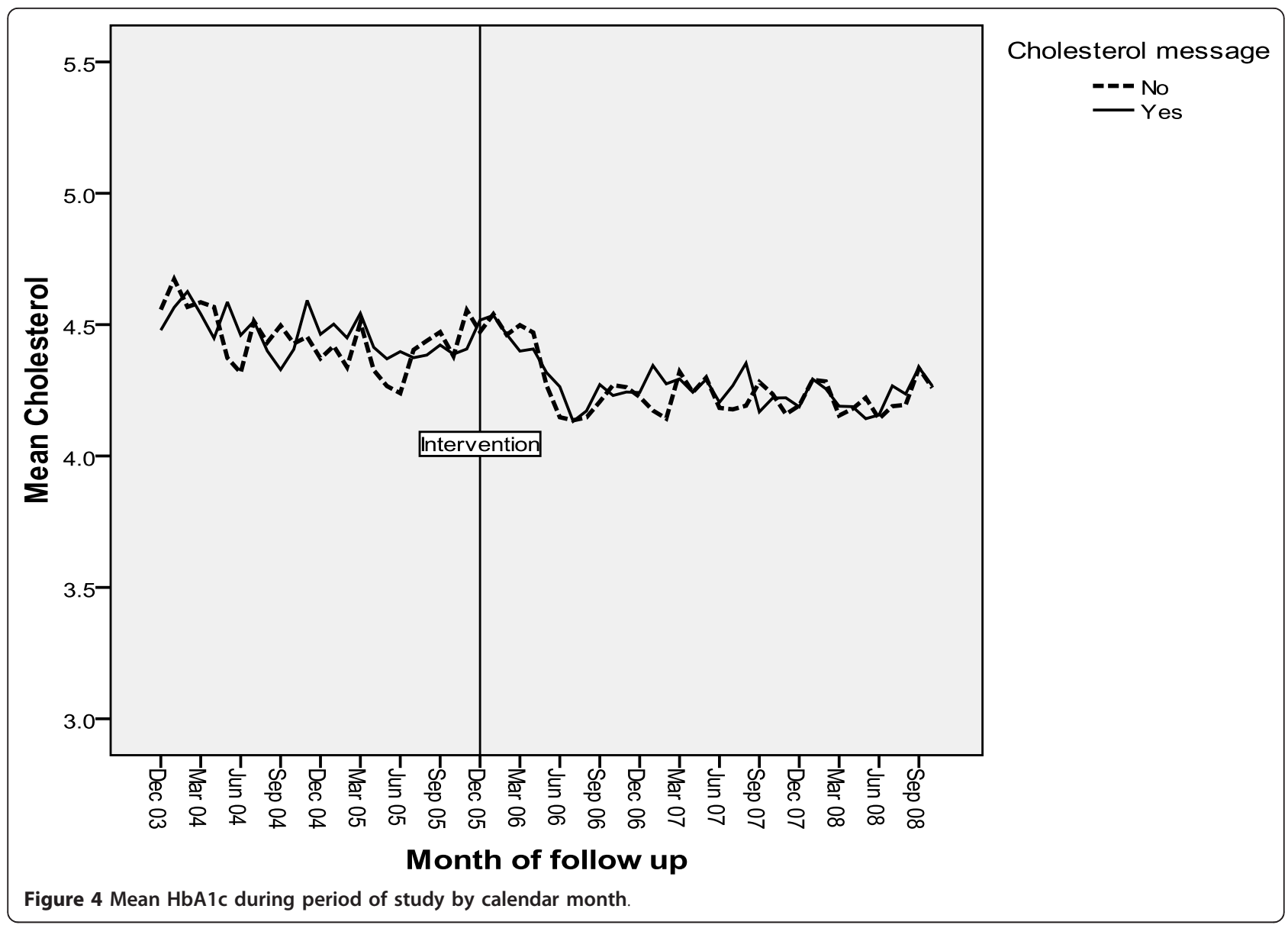

with blood pressure less than 145/85 mmHg [24]. This makes the achievement of improving BP levels and control particularly notable. Against such background levels of achievement in relation to the QOF ( $94 \%$ for checking peripheral pulses in 2009 in Newcastle upon Tyne), it would also be surprising if the increased likelihood of foot inspection was merely attributable to better recording.

Although how well foot inspection was performed is unknown, the observed change is likely to represent a true improvement in care. This is important given the recognised value of multiple risk factor reduction, including for vascular endpoints, in type 2 diabetes [25].

Previous studies of test-ordering messages have demonstrated reductions in request rates [12-14]. This is one of a very few studies aimed at improving appropriate care, and our interventions improved broader aspects of clinical management and patient endpoints. Furthermore, our evaluation on changes in physiological, intermediate outcome, endpoints (rather than rate changes) represented a more stringent test of the effect of the interventions' ability to improve patient care [26]. That the interventions changed both process and intermediate outcome further supports the utility of this method of improving patient care.

The acquisition of more clinical data than originally planned allowed the detection of a statistically significant smaller change in diastolic BP than the trial was originally powered for. Although the small effect on mean diastolic BP is unlikely to be clinically important at an individual level, it approximates to worthwhile population-level benefits. When the coefficients at ages 60 to 69 years from the Prospective Studies Collaboration are applied [27], these diastolic BP reductions produce of the order of a $5 \%$ relative reduction in stroke mortality and $3 \%$ to $4 \%$ falls in mortality from ischaemic heart disease and other vascular causes over 10 years. This mean population effect may be explained by GPs targeting action on patients above the threshold of 140/ $80 \mathrm{mmHg}$, as indicated by the increased odds of patients' BP being controlled in intervention practices.

The increase in HbA1c testing rates suggests that the glycaemic control message influenced practice. Our interpretation of this is that it reflects increased testing in response to increased attempts to improve glycaemic control. The absence of an effect on HbA1c levels may 


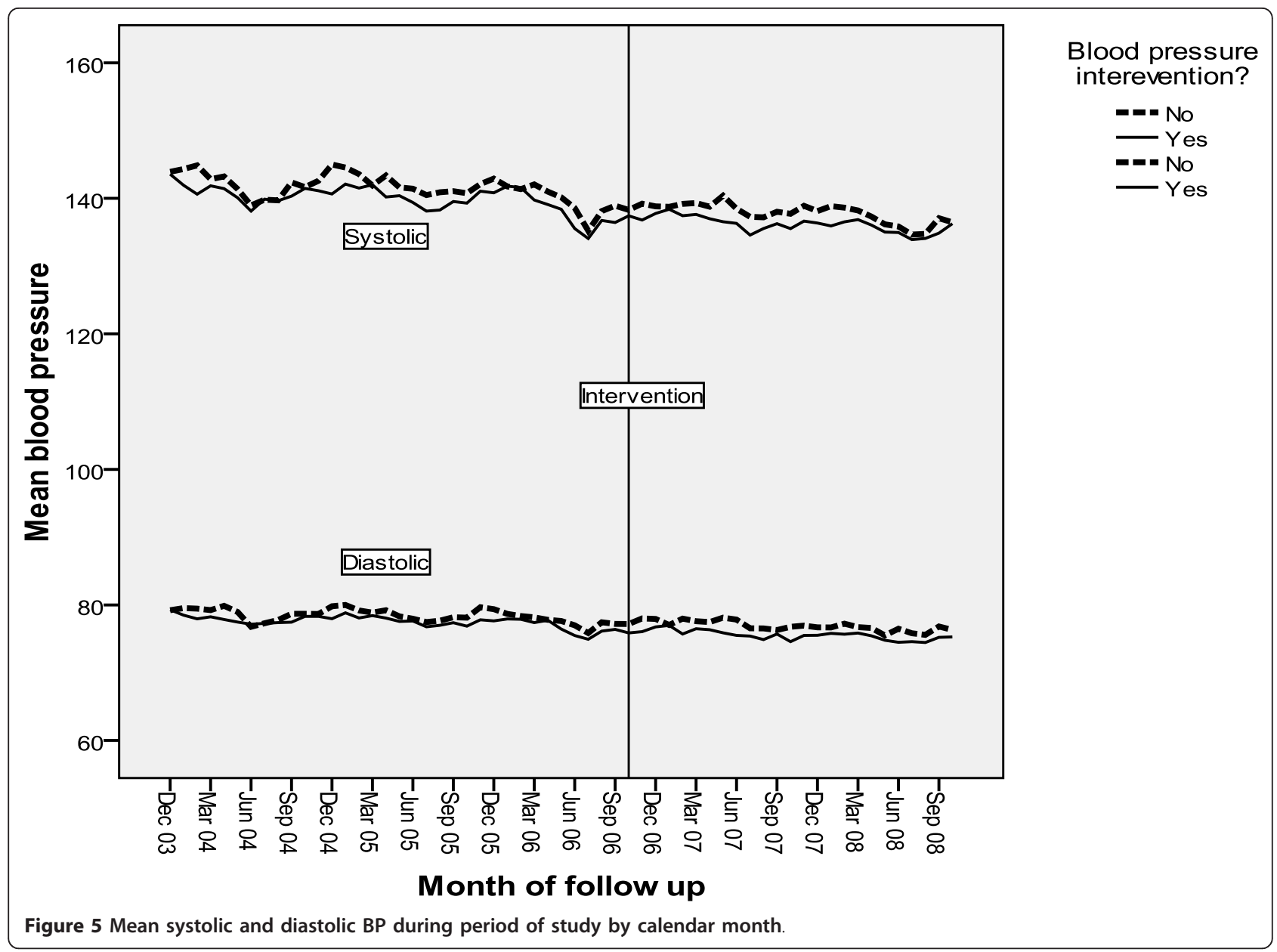

partly reflect the wider range of physiological and compliance issues around improving this endpoint and possible 'ceiling effects'-the mean post-intervention HbA1c for both control and intervention groups (7.5\%) was close to the then QOF target level of $7.4 \%$ or less. Nonetheless, there is still scope for improvement given that $37 \%$ of patients still had levels above this target. More intensive and complex types of intervention may be required to target this problem [9].

The result that the BP message led to worse control in patients with microalbuminuria was unexpected and counterintuitive. We were underpowered for the comparison because we had not anticipated that 11 of the practices would not provide valid data, so the analysis was based on about 1,000 patients from 21 practices compared to the overall $\mathrm{BP}$ analysis that was based on about 7,400 patients from 34 practices. BP control over the entire period of the study was better for patients in practices randomised to receive BP messages than for those in control practices (difference in means of 3.7 and $2.7 \mathrm{~mm} \mathrm{Hg}$ in systolic and diastolic BP, respectively). Thus, there was less room for improvement in practices that received the intervention. The observed effect of the intervention may be a regression to the mean phenomenon given the higher baseline values in the practices that did not receive the BP messages. There is also the possibility that there was something systematically different about the 21 practices that did and the 11 that did not contribute data to this analysis.

Taken together, our findings suggest that there may be a threshold in clinical performance beyond which prompts attached to test results do not work or have only modest effects. The review of point-of-care computer reminders did not find any specific reminder or contextual features significantly associated with effect size [12]. A review of a different behaviour change intervention, audit, and feedback found that lower baseline levels of clinical performance were associated with larger effect size [28]. Therefore, brief educational messages may still have considerable potential to improve practice and merit further exploration in at least three ways. First, their relative effects may vary across different levels of baseline performance, and it is worth actively investigating the modifying effects of baseline performance. They 
Table 3 Estimated impact of the interventions.

\begin{tabular}{|c|c|c|c|c|}
\hline \multirow[t]{2}{*}{ Outcome } & \multicolumn{4}{|c|}{ Effect of intervention } \\
\hline & Parameter $^{\dagger}$ & Estimate $^{\ddagger}$ & $95 \%$ & $\% \mathrm{Cl}$ \\
\hline \multicolumn{5}{|l|}{ Glycaemic control message } \\
\hline $\mathrm{HbA1c}(\%)^{*}$ & mean & 0.01 & -0.03 & 0.04 \\
\hline $\mathrm{HbA1c}$ within target level of control (less than 6.35) & OR & 0.94 & 0.87 & 1.03 \\
\hline Number of $\mathrm{HbA} 1 \mathrm{c}$ tests being ordered in a calendar month & IRR & 1.06 & 1.01 & 1.11 \\
\hline \multicolumn{5}{|l|}{ Cholesterol control message } \\
\hline Cholesterol $\left(\mathrm{mmol} / \mathrm{l}^{*}\right.$ & mean & 0.01 & -0.04 & 0.05 \\
\hline Cholesterol within target level of control $(5 \mathrm{mmol} / \mathrm{l}$ or less) & OR & 1.01 & 0.92 & 1,11 \\
\hline Number of a cholesterol tests being ordered in a calendar month & IRR & 1.00 & 0.95 & 1.05 \\
\hline \multicolumn{5}{|l|}{ Blood pressure control message } \\
\hline 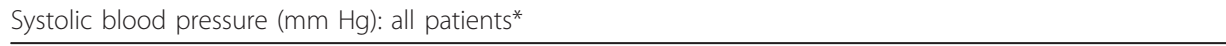 & mean & -0.06 & -0.41 & 0.30 \\
\hline Systolic blood pressure $(\mathrm{mm} \mathrm{Hg})$ : patients with micro-albuminuria from 21 practices & mean & 1.38 & 0.33 & 2.42 \\
\hline Diastolic blood pressure $(\mathrm{mm} \mathrm{Hg})$ : all patients* & mean & -0.52 & -0.73 & -0.32 \\
\hline Diastolic blood pressure $(\mathrm{mm} \mathrm{Hg})$ : patients with micro-albuminuria from 21 practices & mean & 0.61 & 0.03 & 1.19 \\
\hline Blood pressure within target level of control (less than or equal to 140/80): all patients & OR & 1.05 & 1.00 & 1.10 \\
\hline Blood pressure within target level of control (less than or equal to 130/80): patients with micro-albuminuria & OR & 0.88 & 0.78 & 0.99 \\
\hline \multicolumn{5}{|l|}{ Foot inspection message } \\
\hline Number of patients in practice for whom a foot inspection was recorded in a calendar month* & IRR & 1.26 & 1.18 & 1.36 \\
\hline \multicolumn{5}{|l|}{ tNotes } \\
\hline \multicolumn{5}{|l|}{ - mean: change in mean that can be attributed to the intervention } \\
\hline \multicolumn{5}{|l|}{ - OR: odds ratio (relative increase in odds of stated outcome) } \\
\hline \multicolumn{5}{|l|}{ - IRR: incidence rate ratio (relative increase in likelihood of stated outcome) } \\
\hline \# Estimates adjusted for strata used when randomising practices. & & & & \\
\hline 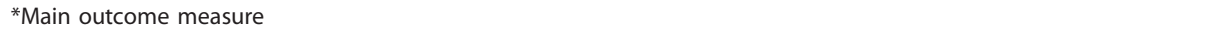 & & & & \\
\hline
\end{tabular}

may work best as an initial intervention where there have been no previous efforts to improve performance and levels of appropriate performance are relatively low. Second, the impact of such interventions may be strengthened by better adapting them more specifically to clinician and patient needs $[29,30]$. The conditional messages (HbA1c control and ACR/BP), where a specific clinical action was recommended on the basis of a test result, were very simple and had mixed effects. Third, many clinical decisions are based upon laboratory results. The advent of real-time, interactive computerised requesting and reporting systems provides opportunities to readily identify candidate tests or conditions and then to influence practice both as requests are made and reports received, thereby allowing more efficient targeting of test request messages.

Study strengths included the use of a randomised design allowing us to be confident that any observed effects could therefore be attributed to the interventions, despite other quality improvement initiatives affecting diabetes care during the time of the study $[31,32]$. We are confident of fidelity given that our routine checks on the messages received revealed no deviations from randomised assignment. We used reliably coded data with minimally intrusive data collection, conducted after the intervention period was complete, that captured any effects on whole practice populations, thereby preventing any selection bias attributable to differential recruitment within randomised clusters [33]. We examined long-term outcomes (at least 24 months), thereby affording greater confidence in the sustainability of any effects.

There were several limitations. First, the study took place in one geographical area with limited patient ethnic diversity [34], so it is unclear how our results would translate into a setting with a higher ethnicity-related prevalence of diabetes. However, given that our trial involved a population of primary care practices with higher than average levels of performance for diabetes care, our estimated effects may be relatively conservative $[18,24]$. Second, practices on the borders of Newcastle could also conceivably have used other hospital laboratories, thereby diluting intervention effects. However, this is unlikely to be a major issue given that laboratory services are usually arranged as part of block contracts with local hospital services. Third, we do not know if the messages were actually read by clinical practice staff, especially by those responsible for acting upon results. Fourth, as we assessed one main outcome for each of four randomised interventions, we cannot rule out type 
1 error as an explanation for the statistically significant effect on diastolic BP. Fifth, we did not perform an economic analysis. Whilst the intervention had low set up and negligible costs, any relative cost-effectiveness might be reduced by increased test ordering (for HbA1c), prescribing, or consultations. Finally, as an empirical intervention, we do not have any insight into how or why the intervention did or did not work. Further research is needed to understand the processes by which apparently simple interventions work.

\section{Conclusion}

Brief educational messages attached to laboratory test results represent a simple and sustainable way to bring about improvements in care. We have demonstrated that messages aimed to improve care-produced effects on clinical practice to varying degrees, including changes in patient endpoints that may be worthwhile at a population level. These changes occurred over and above the background effects of a major pay-for-performance programme for primary care practice in a geographical area with historically high levels of performance. Given that the vast majority of studies of this type of intervention aim to decrease inappropriate test use, educational prompts aimed at improving care merits further research to identify the most appropriate clinical contexts where they can effectively target practice, explore how they work and means of enhancing their effects, and assess their cost-effectiveness.

\section{Acknowledgements \\ Newcastle Primary Care NHS Trust and the Newcastle Upon Tyne Hospitals Charity funded this study. The funders of this study had no role in study design, data analysis, data collection, data interpretation, or writing of the report. The views expressed are those of the authors and not necessarily of the funding bodies. The work of Barney Ulyatt, Reg Etheridge and Rachel Wright from Newcastle PCT was invaluable in ensuring data collection. We thank Julia Critchley, for advice on, and calculation of, cardiovascular risk, and Mike Casselden for the insights he offered whilst representing health service users' perspectives on the Steering Group. We are also grateful to all primary care practices which participated and contributed data. Jeremy Grimshaw holds a Canada Research Chair in Health Knowledge Transfer and Uptake.}

\begin{abstract}
Author details
${ }^{1}$ Leeds Institute of Health Sciences, Charles Thackrah Building, University of Leeds, 101 Clarendon Road, Leeds LS2 9LJ, UK. ${ }^{2}$ Institute of Health and Society, Newcastle University, The Baddiley-Clark Building, Richardson Road, Newcastle upon Tyne, NE2 4AX, UK. ${ }^{3}$ Newcastle NHS Primary Care Trust, Newcastle Diabetes Centre, Newcastle General Hospital, Newcastle upon Tyne, NE4 6BE, UK. ${ }^{4}$ Clinical Biochemistry, Newcastle Upon Tyne Hospitals NHS Foundation Trust, Royal Victoria Infirmary, Queen Victoria Road, Newcastle upon Tyne, NE1 4LP, UK. ${ }^{5}$ Department of Clinical Biochemistry, Aberdeen University Medical School, Polwarth Building, Aberdeen, AB25 2ZD, UK. ${ }^{6}$ Clinical Epidemiology Program, Ottawa Health Research Institute, 725 Parkdale Avenue, Ottawa, ON K1Y 4E9, Canada.
\end{abstract}

\section{Authors' contributions}

MPE conceived the project. RF was principal investigator. All authors contributed to the design of the study. SH, RF, and IG were responsible for running the project. NS was responsible for the statistical analyses. All authors interpreted the data and findings. RF wrote the first draft of the manuscript, all authors commented on it and all further revisions. All authors read and approved the final manuscript. RF is guarantor for the paper.

\section{Competing interests}

MPE is Co-Editor in Chief, RF is Deputy Editor and JG is on the Editorial Board of Implementation Science. All decisions on this manuscript were made by another editor.

Received: 7 May 2011 Accepted: 16 December 2011 Published: 16 December 2011

\section{References}

1. Hoerger T, Segel J, Gregg E, Saaddine J: Is glycemic control improving in U.S. adults? Diabetes Care 2008, 31:81-86.

2. Cooper J, Claudi T, Jenum A, Thue G, Hausken M, Ingskog W, Sandberg S: Quality of Care for Patients With Type 2 Diabetes in Primary Care in Norway Is Improving: Results of cross-sectional surveys of 33 general practices in 1995 and 2005. Diabetes Care 2009, 32:81-83.

3. Campbell S, Reeves D, Kontopantelis E, Sibbald B, Roland M: Effects of Pay for Performance on the Quality of Primary Care in England. N Engl J Med 2009, 361:368-378.

4. Audit Commission: Testing Times: A Review of Diabetes Services in England and Wales. London: Audit Commission; 2000.

5. Saaddine J, Cadwell M, Gregg E, Engelgau M, Vinicor F, Imperatore G, Narayan K: Improvements in Diabetes Processes of Care and Intermediate Outcomes: United States, 1988-2002. Ann Intern Med 2006, 144:465-474

6. Verma A, Birger H, Bhatt J, Murray C, Saxena R, Banarsee S, Gnani S, Majeed A: Ethnic disparities in diabetes management: a 10-year population-based repeated cross-sectional study in UK primary care. $J$ Public Health 2010, 32:fdp114v111-fdp114.

7. Rossi M, Nicolucci A, Arcangeli A, Cimino A, De Bigontina G, Giorda C, Meloncelli I, Pellegrini F, Valentini U, Vespasiani G, on behalf of the Associazone Medici Diabetologi: Baseline Quality-of-Care Data From a Quality-Improvement Program Implemented by a Network of Diabetes Outpatient Clinics. Diabetes Care 2008, 31:2166-2168.

8. The NHS Information Centre: National Diabetes Audit Executive Summary 2008-2009. 2010.

9. Shojania KG, Ranji SR, McDonald KM, Grimshaw JM, Sundaram V, Rushakoff RJ, Owens DK: Effects of quality improvement strategies for type 2 diabetes on glycemic control: a meta-regression analysis. JAMA 2006, 296:427-440

10. Craig P, Dieppe P, Macintyre S, Michie S, Nazareth I, Petticrew M: Developing and evaluating complex interventions: the new Medical Research Council guidance. BMJ 2008, 337:a1655.

11. Grimshaw JM, Thomas RE, MacLennan G, Fraser C, Ramsay CR, Vale L, Whitty P, Eccles MP, Matowe L, Shirran L, Wensing M, Dijkstra R, Donaldson C: Effectiveness and efficiency of guideline dissemination and implementation strategies. Health Technol Assess 2004, 8(6).

12. Shojania KG, Jennings A, Mayhew A, Ramsay CR, Eccles MP, Grimshaw J: The effects of on-screen, point of care computer reminders on processes and outcomes of care. Cochrane Database of Systematic Reviews 2009, , 3: CD001096.

13. Eccles M, Steen N, Grimshaw J, Thomas L, McNamee P, Soutter J, Wilsdon J, Matowe L, Needham G, Gilbert F, Bond S: Effect of audit and feedback, and reminder messages on primary-care radiology referrals: a randomised trial. Lancet 2001, 357:1406-1409.

14. Thomas RE, Croal BL, Ramsay C, Eccles M, Grimshaw J: Effect of enhanced feedback and brief educational reminder messages on laboratory test requesting in primary care: a cluster randomised trial. Lancet 2006, 367:1990-1996.

15. Solomon $\mathrm{DH}$, Hashimoto $H$, Daltroy L, Liang MH: Techniques to improve physician's use of diagnostic tests. JAMA 1998, 280:2020-2027.

16. Foy R, Hawthorne G, Gibb I, Eccles MP, Steen N, Hrisos S, White T, Croal BL, Grimshaw JM: A cluster randomised controlled trial of educational prompts in diabetes care: study protocol. Implementation Science 2007, 2:22.

17. Roland M: Linking Physicians' Pay to the Quality of Care - A Major Experiment in the United Kingdom. N Engl J Med 2004, 351:1448-1454

18. The Health and Social Care Information Centre: Quality and Outcomes Framework. Online GP practice results database. 2010, 2010. 
19. Donner A, Birkett N, Buck C: Randomization by cluster. Sample size requirements and analysis. Am J Epidemiol 1981, 114:906-914.

20. Campbell MK, Thompson S, Ramsay CRMGS, Grimshaw JM: Sample size calculator for cluster randomised trials. Comput Biol Med 2004, 34:113-125.

21. Eccles MP, Whitty PM, Speed C, Steen IN, Vanoli A, Hawthorne G, Grimshaw J, Wood LJ, McDowell D: A pragmatic cluster randomised controlled trial of a Diabetes REcall And Management system: the DREAM trial. Implementation Science 2007, 2:6-6.

22. Campbell MK, Mollison J, Grimshaw JM: Cluster trials in implementation research: estimation of intracluster correlation coefficients and sample size. Statist Med 2001, 20:391-399.

23. Ramsay CR, Matowe L, Grilli R, Grimshaw JM, Thomas RE: Interrupted time series designs in implementation research: lessons from two systematic reviews of behaviour change strategies. International Journal of Health Technology Assessment 2002, 19:613-623.

24. NHS Information Centre for Health and Social Care: National Diabetes Audit. 2010

25. Gæde P, Vedel P, Larsen N, Jensen G, Parving H, Pedersen O: Multifactorial Intervention and Cardiovascular Disease in Patients with Type 2 Diabetes. N Engl J Med 2003, 348:383-393.

26. Brown C, Hofer T, Johal A, Thomson R, Nicholl J, Franklin B, Lilford R: An epistemology of patient safety research: a framework for study design and interpretation. Part 3. End points and measurement. Qual Saf Health Care 2008, 17:170-177.

27. Lewington S, Clarke R, Qizilbash N, Peto R, Collins R, Prospective Studies C: Age-specific relevance of usual blood pressure to vascular mortality: a meta-analysis of individual data for one million adults in 61 prospective studies. Lancet 2002, 360:1903-1913.

28. Jamtvedt G, Young JM, Kristoffersen DT, O'Brien MA, Oxman AD: Audit and feedback: effects on professional practice and health care outcomes. Cochrane Database of Systematic Reviews 2006, , 2: CD000259.

29. Rousseau N, McColl E, Newton J, Grimshaw J, Eccles M: Practice based longitudinal, qualitative interview study of computerised evidence based guidelines in primary care. BMJ 2003, 326:314-318.

30. Baker R, Camosso-Stefinovic J, Gillies C, Shaw E, Cheater F, Flottorp S, Robertson N: Tailored interventions to overcome identified barriers to change: effects on professional practice and health care outcomes. Cochrane Database of Systematic Reviews 2010, 3: CD005470.

31. Eccles M, Grimshaw JM, Campbell M, Ramsay C: Research designs for studies evaluating the effectiveness of change and quality improvement strategies. Qual Saf Health Care 2003, 12:47-52.

32. Doran T, Fullwood C, Gravelle H, Reeves D, Kontopantelis E, Hiroeh U, Roland M: Pay-for-Performance Programs in Family Practices in the United Kingdom. N Engl J Med 2006, 355:375-384.

33. Farrin $A$, Russell $I$, Torgerson $D$, Underwood $M$, on behalf of the UK BEAM Trial team: Differential recruitment in a cluster randomized trial in primary care: the experience of the UK Back pain, Exercise, Active management and Manipulation (UK BEAM) feasibility study. Clinical Trials 2005, 2:119-124.

34. Census 2001 profiles. [http://www.statistics.gov.uk/census2001/profiles/00cj. asp].

doi:10.1186/1748-5908-6-129

Cite this article as: Foy et al.: A cluster randomised trial of educational messages to improve the primary care of diabetes. Implementation Science 2011 6:129.

\section{Submit your next manuscript to BioMed Central and take full advantage of:}

- Convenient online submission

- Thorough peer review

- No space constraints or color figure charges

- Immediate publication on acceptance

- Inclusion in PubMed, CAS, Scopus and Google Scholar

- Research which is freely available for redistribution

Submit your manuscript at www.biomedcentral.com/submit
Biomed Central 